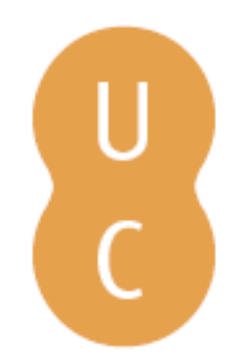

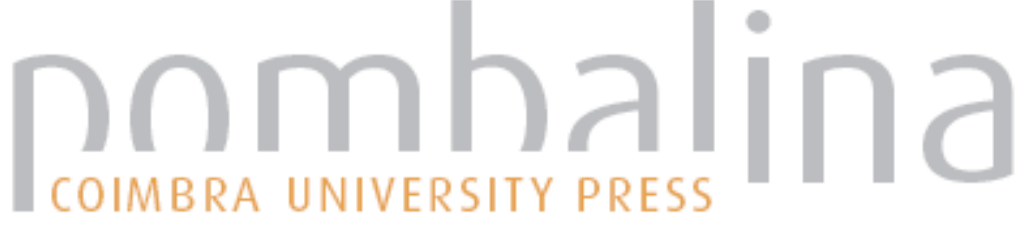

\section{Huyendo del insularismo teatral: la pasión según Antígona Pérez}

Autor(es): $\quad$ Ramos Escobar, José Luis

Publicado por: Centro de Estudos Clássicos e Humanísticos da Universidade de

URL

persistente: URI:http://hdl.handle.net/10316.2/30275

DOI: $\quad$ DOI:http://dx.doi.org/10.14195/978-989-721-038-9_48

Accessed : $\quad$ 26-Apr-2023 02:51:24

A navegação consulta e descarregamento dos títulos inseridos nas Bibliotecas Digitais UC Digitalis, UC Pombalina e UC Impactum, pressupõem a aceitação plena e sem reservas dos Termos e Condições de Uso destas Bibliotecas Digitais, disponíveis em https://digitalis.uc.pt/pt-pt/termos.

Conforme exposto nos referidos Termos e Condições de Uso, o descarregamento de títulos de acesso restrito requer uma licença válida de autorização devendo o utilizador aceder ao(s) documento(s) a partir de um endereço de IP da instituição detentora da supramencionada licença.

Ao utilizador é apenas permitido o descarregamento para uso pessoal, pelo que o emprego do(s) título(s) descarregado(s) para outro fim, designadamente comercial, carece de autorização do respetivo autor ou editor da obra.

Na medida em que todas as obras da UC Digitalis se encontram protegidas pelo Código do Direito de Autor e Direitos Conexos e demais legislação aplicável, toda a cópia, parcial ou total, deste documento, nos casos em que é legalmente admitida, deverá conter ou fazer-se acompanhar por este aviso.

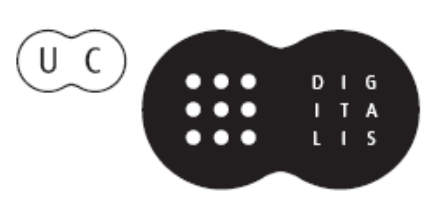




\section{De ayer a hoy}

\section{Influencias clásicas en la literatura}

\section{Aurora López, Andrés Pociña, Maria de Fátima Silva (coords.)}




\section{HuYENDO DEL INSULARISMO TEATRAL. LA PASIÓN SEGÚN ANTÍGONA PÉREZ}

José Luis Ramos Escobar Universidad de Puerto Rico

No es hasta 1967 cuando las formas clásicas se funden con situaciones del momento histórico en la obra La pasión según Antígona Pérez. El punto de partida de Luis Rafael Sánchez fue la dictadura en República Dominicana de Rafael Leonidas Trujillo y Molina y el asesinato de las hermanas Mirabal. El análisis comparativo nos brinda el asidero para examinar la construcción dramática en la que se entrelazan técnicas brechtianas con el mito griego y situaciones contemporáneas Los elementos intertextuales y extratextuales son factores determinantes para el análisis intratextual de la perviviencia del mito de Antígona en el teatro puertorriqueño.

Como preámbulo a este congreso y a esta ponencia, el Festival de Teatro Clásico de Mérida en España acaba de presentar en julio tres Antígonas, oscilando entre versiones, adaptaciones y recreaciones. Miguel Murillo, Ernesto Caballero y Emilio del Valle son los dramaturgos representados en esta triada que demuestra la pertinencia del estudio de la pervivencia de las formas clásicas en el teatro contemporáneo.

En el caso del teatro puertorriqueño esta tendencia ha sido poco explorada por la crítica contemporánea. Paradójicamente, la incursión en el teatro clásico griego se correlaciona con el desarrollo del teatro moderno en la isla, llamado por algunos como teatro nacional puertorriqueño. Las primeras muestras significativas ocurren en 1938, año clave para el desarrollo del teatro puertorriqueño. En el certamen auspiciado por el Ateneo Puertorriqueño, celebrado en dicho año, obtuvo el primer premio El clamor de los surcos, obra de Manuel Méndez Ballester que utiliza la forma de la tragedia para plasmar el declive y posterior caída de los hacendados del país Dos años después Méndez recurre con mayor acierto a la forma de la tragedia en Tiempo muerto. Una década después, Méndez trató de adaptar la historia de Edipo a situaciones contemporáneas en Hilarión, pero el resultado fue poco auspicioso. René Marqués intentó asimismo verter acuciantes problemas del momento en moldes clásicos en la obra La muerte no entrará en palacio, utilizando incluso a personajes griegos como Tiresias como parte de la trama. Sin embargo, no será hasta 1967 cuando las formas clásicas se fundan con situaciones del momento histórico de manera más creativa y con mayor profundidad en la acción dramática en la obra La pasión según Antígona Pérez. Utilizando la historia de la hija de Edipo según plasmada por Sófocles, Luis Rafael Sánchez 
traspone los personajes principales al ámbito de los dictadores y la lucha por la emancipación en América Latina. El punto de partida de Luis Rafael Sánchez fue la dictadura en República Dominicana de Rafael Leonidas Trujillo y el asesinato de las hermanas Patria, Minerva y María Teresa Mirabal y de sus compañeros de lucha el 25 de noviembre de 1960. Este hecho fue recogido por Julia Álvarez en su novela En el tiempo de las mariposas y recreado por Mario Vargas Llosa en La fiesta del chivo.

La literatura puertorriqueña, y el teatro en particular, se habían quedado encerrados en los parámetros insulares, con muy poca vinculación con las corrientes y tendencias latinoamericanas y mundiales, y con un total predominio de temas y situaciones isleños. Antonio S. Pedreira fue quien definió de manera certera esta situación con su libro Insularismo de 1934. En la década de 1960 se afirmaba que ningún texto u obra puertorriqueña podía entenderse fuera de la isla. Se llegó al extremo de exigir que ninguna obra podía incluir personajes extranjeros. Contra ese ostracismo creativo reacciona Luis Rafael Sánchez, quien había comenzado su creación dramatúrgica en esa década. Sánchez ya había manejado formas y personajes clásicos en su obra La hiel nuestra de cada día (1961), utilizando a Píramo y Tisbe como referentes para recrear la terrible pobreza que agobiaba a los habitantes del Viejo San Juan. Pero fue la feroz dictadura de Trujillo en República Dominicana la que le proveyó a Sánchez y al teatro puertorriqueño la puerta de salida del insularismo y lo vincularon de manera definitiva al teatro latinoamericano y mundial mediante la recreación de la obra de Sófocles y la incorporación de técnicas brechtianas a su obra.

La Antígona de Sánchez tiene apellido: Pérez, lo cual la convierte en prima lejana de la Antígona Vélez de Marechal. Apellidos comunes que le quitan la pátina de realeza al personaje y le brindan un asidero popular a sus acciones como integrante de clases menos favorecidas. Creón también se concretiza contemporáneo con el apellido Molina, apellido materno del dictador Rafael Leonidas Trujillo y Molina. Trujillo nombró a la capital de República Dominicana Ciudad Trujillo, Creón llamó a la suya República de Molina. Insisto en estas correlaciones entre historia y obra porque algunos críticos han intentado inscribir la obra en la ínsula, aludiendo a personas reales de Puerto Rico como el modelo para los personajes de la obra. Proclamar que la nacionalista Olga Viscal Garriga es el punto de partida de Antígona Pérez es un error fomentado por la miopía insularista que aun permea algunos sectores de la crítica en Puerto Rico.

Etéocles y Polinices se transforman en Héctor y Mario Tavárez, quienes han sido asesinados por las fuerzas de seguridad del estado de Molina por sus actividades sediciosas y están expuestos en la plaza pública para escarmiento de sus simpatizantes. La relación de hermanos de Antígona es transformada por Sánchez en la de compañeros en la lucha contra el dictador, estando en la obra 
del puertorriqueño ambos expuestos al escarnio público. Esa transformación es de carácter ideológico, dado que los lazos de solidaridad no tienen fundamento familiar sino de unidad de propósito y de acción. Consciente de las exigencias del mito, Antígona Pérez reclamará que los hermanos Tavárez dejaron de ser sus amigos para convertirse en sus hermanos, porque Antígona necesita hermanos para completar su acción dramática. Hay incluso una referencia a que hubo una relación amorosa entre Antígona y Mario, eco lejano de la vertiente incestuosa que persiguió a la estirpe de Layo. Cuando Creón insinúa que Mario es impotente, Antígona lo refuta: Puedo dar testimonio de lo contrario. Los Tavárez forman parte del estrato extratextual histórico, teniendo como base a Manuel Aurelio Tavárez, esposo de Minerva Mirabal y conspirador junto a ella en contra de Trujillo.

La Ismene de Sófocles es en la obra de Sánchez Irene Domingo y Zuñiga. Aunque el nombre las acerca, Irene no es hermana de Antígona sino su mejor amiga. Su función dramática es, sin embargo, parecida. Irene trata de persuadir a Antígona de que revele el lugar donde enterró a los hermanos Tavárez. Muestra la misma falta de carácter del personaje griego, pero se añade a su cobardía, la traición. Irene ha establecido una relación amorosa con Fernando Curet, el Hemón de Sánchez, joven militar prometido de Antígona. Éste también ha traicionado a Antígona al aceptar una promoción militar que Creón le ha ofrecido para convertirlo en el carcelero de Antígona.

La obra incluye varios personajes de creación del autor, que se distinguen por su función intratextual: Aurora, la madre de Antígona, Monseñor Bernardo Escudero, portavoz de la iglesia, y Pilar Vargas, primera dama de la República de Molina. Todos forman parte del plan de Creón Molina para minar la resistencia de Antígona. La madre recurre a los argumentos estereotipados de la mujer sometida que no debe inmiscuirse en cuestiones de hombres. La defensa que hace Antígona de los deberes y responsabilidades de la mujer constituye un alegato muy vinculado al movimiento de liberación femenina. Monseñor Escudero recurre al chantaje religioso para intentar someter a la obediencia a la rebelde Antígona. Perderás el alma, le advierte el sinuoso monseñor, pero Antígona lo reta: Apostemos, Monseñor. La alianza tácita de los poderes políticos y eclesiásticos sobresale en esta escena, apuntando directamente a la complicidad de la iglesia con algunos regímenes dictatoriales de América Latina. Pilar Vargas, esposa de Creón, funciona al nivel intertextual como Lady Macbeth: instiga, aguijonea y manipula a Creón a que imponga su poder sin titubear, sin consideraciones, sin debilidades. Hace gala de su vocación de poder en su encuentro con Antígona, en quien no logra hacer mella en su férrea determinación de mantenerse fiel a sus ideales. Aunque se ha señalado que estos personajes son de procedencia clásica: Aurora/Yocasta; Monseñor Escudero/Tiresias y Pilar Vargas/Eurídice, nada hay en su comportamiento 
ni trayectoria que les acerque a los personajes de Sófocles, como tampoco hay nada en común entre Edipo y Guillermo Pérez, padre de Antígona que se negó a plegarse a los designios de Creón y fue fusilado. Todos ellos son parte de la dramaturgia de Sánchez para darle motivación y causas a la evolución de la trama.

Otra de las elaboraciones dramáticas de Sánchez para la estructuración de la trama es la transformación del coro griego en un coro de periodistas. Vestidos con pantalón negro y chaqueta deportiva, cinco hombres fornidos intervienen a lo largo de la obra para brindar la información oficial sobre el encarcelamiento de Antígona. Los términos lingüísticos utilizados: sediciosa, enemiga del estado, subversiva, facinerosa..., emanan de la terminología que los estados utilizan constantemente para etiquetar a los opositores y críticos del sistema imperante. Los periodistas se convierten así en portavoces al servicio del dictador, promoviendo como hechos la propaganda del poder. Combinan además las noticias sobre levantamientos y luchas sociales a nivel mundial con reportajes sobre las veleidades de las figuras del entretenimiento más banal e intrascendente. Este anclaje en la historia le brinda contexto específico a la trama, a la par que desnuda la función de agente del sistema del periodismo comercial. En consecuencia, el coro no es voz comunal ni representa la visión y los ideales de la sociedad, sino que se convierte en instancia demagógica y deformadora de la realidad.

Creón Molina y Antígona Pérez son los dos grandes personajes de la obra. El primero, que exige el título castrense de Generalísimo, igual que Trujillo, es un maestro de la manipulación, la intimidación y la tortura. Conoce los resortes del poder y sabe aprovecharse de las debilidades de amigos y adversarios. Antígona encarna el compromiso hecho mujer. Es capaz de sacrificarlo todo por la lucha por la libertad y renuncia a la vida de comodidades y lujos que Creón le ofrece en el exilio. Tiene vocación de sacrificio y sabe resistir todas las presiones, tentaciones y vejaciones que recibe para que ceda. Su pasión tiene ribetes cristianos. Desde el título de la obra se establece ese nexo intertextual. La pasión según Antígona Pérez apunta a fórmulas bíblicas, sobre todo al título de los cuatro testimonios de los evangelistas sobre Jesús: El evangelio según... Por eso, la muerte de Antígona se convierte en acto de liberación para los demás, como sucedió con el asesinato de las hermanas Mirabal, que avivó la llama del levantamiento contra Trujillo. Esto culminó con el ajusticiamiento de éste el 30 de mayo de 1961, menos de año después del asesinato de las Mirabal.

La construcción dramática de Sánchez entrelaza además técnicas brechtianas con el mito griego y las situaciones contemporáneas. Sánchez utiliza la técnica del distanciamiento mediante el personaje narrador, la ruptura de la unidad de espacio y la utilización de letreros y carteles como como 
contrapunto histórico para la acción. El inicio mismo de la pieza comienza con Antígona como narradora de su situación: Empecemos por donde se empieza siempre. Nombre, Antígona Pérez. Esa narración consciente del público que presencia su pasión permite al personaje adelantar acciones, como al principio del segundo cuando dice: El segundo acto comenzará verdaderamente cuando Creón me diga: Antígona, te pareces a mí. O cuando viola el concepto de espacio al presentar a Pilar Vargas como Primera Dama de Molina, aunque Antígona está en el sótano y Pilar en los salones del palacio. Al romper con las unidades de tiempo y espacio, la protagonista demuestra que es sujeto de su historia y no objeto que responde a lo que los demás deciden o hacen con respecto a ella. El tiempo y el espacio le pertenecen porque siendo dueña de su historia sabe que va a morir y que las secuencias de la acción desembocarán inevitablemente en su sacrificio. La técnica brechtiana es entonces no sólo una forma de presentar la trama, sino una reafirmación de la función definitoria que la mujer debe desempeñar en la formación, rescate y transformación de nuestras sociedades. El uso de técnicas brechtianas para resaltar la dimensión social de la obra se hace más evidente con el uso de carteles sobre las columnas que sirven de trasfondo a las acciones de los personajes. Dichos carteles llevan consignas claramente políticas sobre la convulsa situación en varios países latinoamericanos. Consignas radicales entonces, aunque ya manoseadas hoy como Yankee go home o Patria o muerte se mezclan con reclamos sobre a quién pertenece el Canal de Panamá o las minas de Bolivia. Incluso hay un guiño del autor para algún espectador perspicaz al incluir la consigna Bosch para presidente, pues juega con el tiempo para decirnos cuál será el futuro tras la caída de Creón Molina. Recuérdese que Juan Bosch fue el primer presidente constitucional después de la erradicación de la dictadura de Trujillo, a quien Creón tipifica. Son referencias lúdicas extratextuales que enriquecen la repercusión de la obra.

Los elementos intertextuales y extratextuales se convierten así en factores fundamentales para el análisis intratextual de la utilización que hace Luis Rafael Sánchez de las formas clásicas para huir del insularismo que ahogaba la creatividad dramatúrgica de los escritores dramáticos del país En consecuencia, Lapasión según Antígona Pérez presenta evidencia sustancial de la pervivencia de dichas formas en el teatro de la menor de las Antillas y del esfuerzo consciente de Luis Rafael Sánchez de latinoamericanizar nuestro teatro y vincularlo a las corrientes más significativas del teatro mundial.

Este ensayo explora la pervivencia de la forma clásica como alternativa al insularismo teatral en Puerto Rico. El análisis comparativo entre Antígona y Antígona Pérez nos brinda el asidero para examinar la construcción dramática de Sánchez en la que se entrelazan técnicas brechtianas con el mito griego y situaciones contemporáneas. Desde el título de la obra se establece otro nexo 
intertextual. La pasión según Antígona Pérez apunta a fórmulas bíblicas, sobre todo al título de los cuatro testimonios de los evangelistas sobre Jesús: E1 evangelio según... Los elementos intertextuales y extratextuales se convierten así en factores fundamentales para el análisis intratextual de la perviviencia del mito de Antígona en el teatro puertorriqueño. 